\begin{tabular}{|c|c|c|}
\hline $\begin{array}{l}\text { ISSN 2525-4812 (versão online) } \\
\text { ISSN 2238-7641 (versão impressa) } \\
\text { http://www.revistaterceiramargem.com/ } \\
\text { index.php/terceiramargem/index }\end{array}$ & $\begin{array}{c}\text { Recebido em: 30/6/2019 } \\
\text { Aprovado em: 13/1/2020 } \\
\text { Período de publicação: jan., } 2021\end{array}$ & $\begin{array}{c}\text { Revista Terceira } \\
\text { Margem Amazônia } \\
(\text { v. } 6 \cdot \text { n. especial } 16 \cdot \text { Jan. } 2021)\end{array}$ \\
\hline
\end{tabular}

Como citar o artigo:

MORAIS JÚNIOR, H. S.; RIBEIRO, R. R. De onde o gelo derrete também é Amazônia. Revista Terceira Margem Amazônia. v. 6, n. especial 16, p. 65-83, 2021. DOI: http://dx.doi.org/10.36882/2525-4812.2021v6i16.ed.esp.p65-83

\title{
DE ONDE O GELO DERRETE TAMBÉM É AMAZÔNIA
}

\author{
Hélio de Souza Morais Júnior ${ }^{1}$ \\ Rafael da Rocha Ribeiro ${ }^{2}$
}

\begin{abstract}
Resumo: Este artigo irá realizar uma reflexão impulsionada pelo debate sobre as mudanças do clima, associado ao derretimento das geleiras tropicais sul-americanas - geleiras da Amazônia -, e suas consequências para a Bacia Amazônica, tomando por base aspectos geológicos e hidrográficos desde a região cisandina até o Golfão Marajoara, tendo como fio condutor o Rio Amazonas. Nesse contexto, pontua-se o papel do desmatamento da Amazônia Legal Brasileira, da monocultura e mineração em países da Amazônia andina que corroboram para um cenário regional climático conflituoso, bem como reorganização de políticas de integração sul-americana tais como o Tratado de Cooperação Amazônica (TCA) e da Iniciativa para Integração da Infra-Estrutura Regional Sul-Americana (IIRSA) na elaboração e concretização da geopolítica regional que mantém uma concepção subalterna de fronteira de commodities para a expansão capitalista neoextrativista na Pan-Amazônia. Nesse sentido, argumenta-se que a manutenção das geleiras da Amazônia deve ter a mesma compreensão e seriedade que se tem sobre a importância de salvaguardar a biodiversidade da região mantendo a floresta amazônica em pé.
\end{abstract}

Palavras-chave: geleiras da Amazônia, Golfão Marajoara, geopolítica, mudanças do clima.

\section{WHERE THE ICE MELTS IS ALSO THE AMAZON}

\begin{abstract}
This article will carry out a reflection driven by the debate on climate change, associated with the melting of South American tropical glaciers - glaciers in the Amazon -, and their consequences for the Amazon basin, based on geological and hydrographic aspects from the cisandine region to the marajoara gulf, with the Amazon River as its main thread. In this context, the role of deforestation in the Brazilian Legal Amazon, monoculture and mining in countries of the Andean Amazon that corroborate a conflicting regional climate scenario is highlighted, as well as reorganization of South American integration policies such as the Amazon Cooperation Treaty (TCA) and the Initiative for the Integration of South American Regional Infrastructure (IIRSA) in the elaboration and concretization of the regional geopolitics that

\footnotetext{
${ }^{1}$ Geógrafo, D. Sc. em Geociências, professor da Universidade Federal do Rio Grande do Sul (UFRGS), Porto Alegre, RS.

E-mail: heliomorais@ufpa.br

(D) https://orcid.org/0000-0002-3623-5173

2 Geógrafo, Especialização em Geografia e Meio Ambiente. E-mail: r.ribeiro@ufrgs.br

(iD) https://orcid.org/0000-0001-9743-6780
} 
maintains a subordinate conception of the commodities frontier for the neo-extractive capitalist expansion in Pan-Amazon. In this sense, it is argued that the maintenance of glaciers in the Amazon must have the same understanding and seriousness as the importance of safeguarding the region's biodiversity by keeping the Amazon forest standing.

Key words: glaciers of the Amazon, Marajoara Golf, geopolitics, climate change.

\section{Conectando o Sistema...}

Analisar as condições ambientais das geleiras tropicais da América do Sul, identificando seu avanço ou retração e as implicações que isso pode trazer para o sistema hidrológico da Bacia Amazônica, é fundamental para compreender as possíveis consequências das mudanças climáticas em curso sobre a região. De acordo com relatório do Painel Intergovernamental sobre Mudanças Climáticas (IPCC em inglês), o derretimento das geleiras tropicais pode alterar o ciclo hidrológico da Bacia Hidrográfica Amazônica e tal efeito é conferido em nível alto na atribuição à mudança climática (INTERGOVERNMENTAL PANEL ON CLIMATE CHANGE, 2014).

Neste artigo, a reflexão que segue vai ao encontro do pressuposto supracitado. Realizaremos um debate geopolítico que envolve a imensa região amazônica, dando ênfase a alguns aspectos do ponto de vista geológico e hidrológico, na tentativa de evidenciar um fio condutor que conecte a fisiografia amazônica, desde as cordilheiras andinas até o Golfão Marajoara (litoral noroeste do estado do Pará), encanastrada em uma geopolítica que não é somente do âmbito regional, mas principalmente internacional, atualmente - início da segunda década do século XXI -, a Amazônia permanecendo como uma fronteira de recursos naturais subserviente ao neoextrativismo capitalista.

O fio condutor dessa reflexão será sobre essas duas paisagens, Cordilheira dos Andes e Golfão Marajoara, compreendendo-as como componentes de uma mesma totalidade paisagística, obviamente sem esquecer suas distinções fisiográficas, mas tendo o Rio Amazonas - e seus inúmeros tributários - como o elemento que acopla e unifica essas paisagens naturais em uma totalidade. Chama-se especial atenção para o termo totalidade aqui utilizado, pois este tem por fim uma concepção diligente no entendimento para essa região. Tal qual José Coelho da Gama e Abreu, o Barão de Marajó, na obra As Regiões Amazônicas, estudos chorographicos dos estados do Gram Pará e Amazonas de 1895 (ABREU, 1992), mostrou ao fim do século XIX, discorrendo sobre a conjunção hidrográfica desde as terras mais elevadas até as terras mais baixas, as disputas geopolíticas, territoriais e cartográficas entre os países cujas fronteiras estão na região amazônica, a ponto de envolverem até o grande geógrafo prussiano Alexander Von Humboldt (1769-1859) sobre a celeuma do tratado de limites e navegação assinado em 5 maio de 1859 entre Brasil e Venezuela ${ }^{3}$.

\footnotetext{
De acordo com Barão de Marajó (ABREU, 1992), em 1854 Humboldt realizou um estudo, a pedido do então ministro e diplomata brasileiro Miguel Maria Lisboa, o barão de Japurá (1809-1881), revisando cartas e mapas do Tratado de Santo Ildefonso assinado entre Portugal e Espanha em $1^{\circ}$ de outubro de 1777 (ABREU, 1992).
} 


\section{...Dos Andes ao Golfão Marajoara}

\section{De onde o gelo derrete também é Amazônia...}

A Bacia Hidrográfica Amazônica encontra-se sobre dois grandes domínios estruturais - a plataforma sul-americana e a Cordilheira dos Andes, a oeste. Sua expressão é da ordem de abranger seis dos onze países sul-americanos. De acordo com Soares (1991), os rios dessa bacia escoam cerca de um quinto do volume de água doce de todo o planeta, só o Rio Amazonas carrega de $15 \%$ a $20 \%$ da água que todos os rios do mundo conduzem para os oceanos. A Agência Nacional de Água (BRASIL, 2013) estima que a rede hidrográfica da Bacia Amazônica seja a de maior extensão do mundo, aproximadamente $6.110 .000 \mathrm{~km}^{2}$. Em pesquisa desenvolvida pelo Instituto Nacional de Pesquisas Espaciais (INPE, 2008), com técnicas de sensoriamento remoto, identificou-se que o Rio Amazonas tem uma extensão precisa de $6.992 \mathrm{~km}, 140$ a mais que o Rio Nilo, até então considerado o maior rio em extensão do mundo. As primeiras águas que dão origem ao Rio Amazonas descem de uma pequena nascente glacial, localizada na geleira Quehuisha (Figura 1), a uma altura de 5.170 m.s.n.m, nas coordenadas $15^{\circ} 24^{\prime} 24^{\prime \prime} \mathrm{S}$ e $72^{\circ} 9^{\prime} 59^{\prime \prime} \mathrm{O}$, na Cordilheira Chila, no departamento de Arequipa, no Peru (GOICOCHEA, 1996). Essas águas percorrem, desde a nascente até a foz, uma distância de aproximadamente $3.000 \mathrm{~km}$ em linha reta, praticamente a distância entre a cidade de Belém e a cidade de São Paulo.

Figura 1. Representação da Bacia Hidrográfica Amazônica e a localização da nascente do Rio Amazonas (elaboração dos autores).

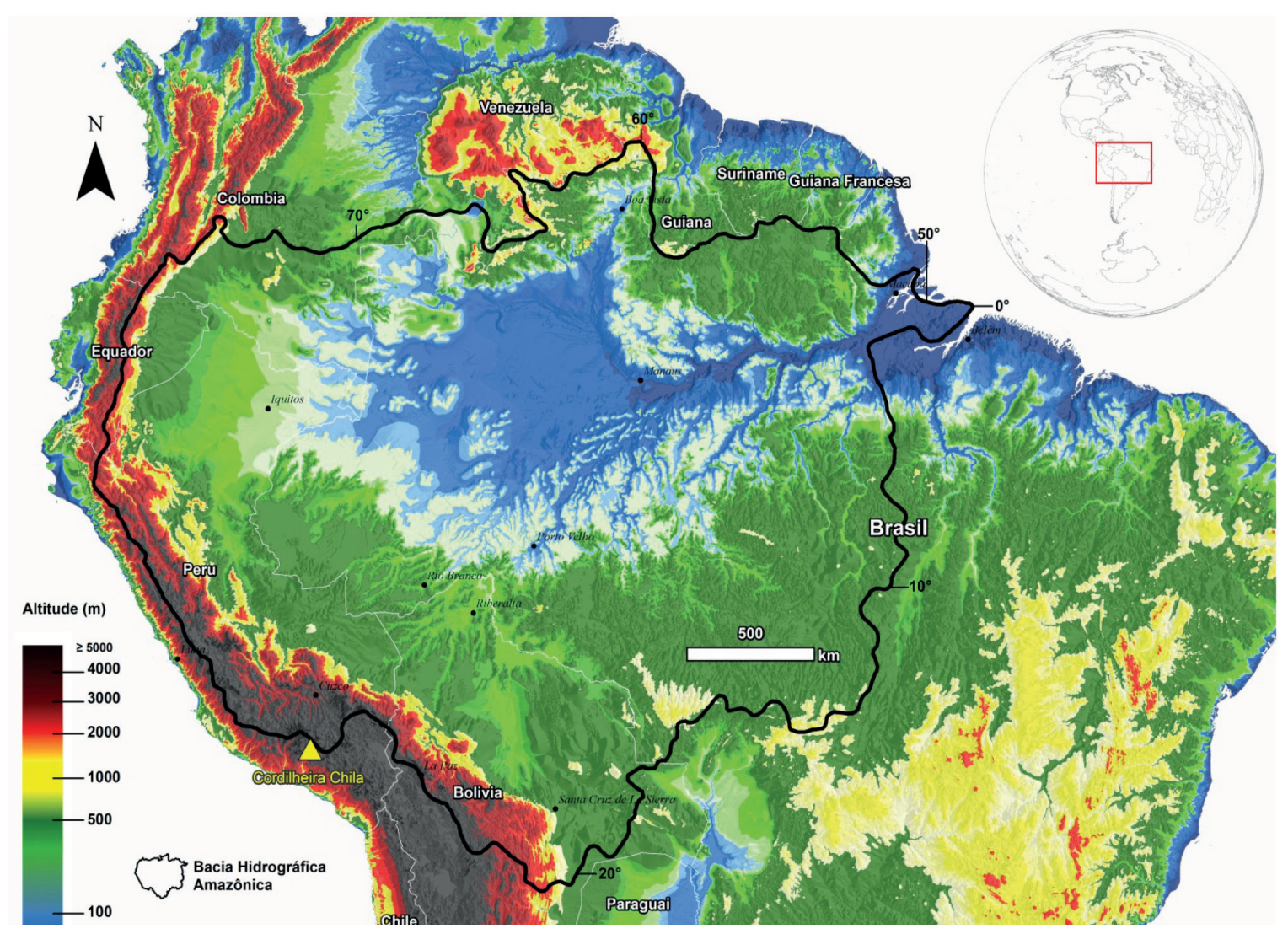

Fonte: Para representação da Bacia Hidrográfica Amazônica utilizou-se o relatório GEO Amazônia do PNUMA/OTCA (2008). Para fronteiras internacionais utilizaram-se os dados de UNEP/GRID (PNUMA) Genebra (http://www.geodata/grid.unep.ch). Para representação topográfica utilizou-se o Modelo Digital de Elevação do Projeto SRTM (Shuttle Radar Topography Mission, em inglês) obtido pelo Earth Explorer USGS (https://earthexplorer.usgs.gov). 
A representação no mapa da Figura 1, associado à Tabela 1, é da Bacia Amazônica constituída por critérios hidrográficos, de acordo com o relatório Perspectivas do Meio Ambiente na Amazônia - GEO Amazônia das Nações Unidas para o Meio Ambiente (PNUMA) e da Organização do Tratado de Cooperação Amazônica (OTCA) e em colaboração com o Centro de Pesquisa da Universidad del Pacífico (CIUP) (GEO..., 2008). Assim, o Brasil tem aproximadamente $62,97 \%$ de território da região, o correspondente a $43,87 \%$ do território nacional. Por conseguinte, o Peru tem 16,57\%, a Bolívia 12,36\%, a Colômbia 5,53\%, o Equador 1,77\% e a Venezuela $0,78 \%$.

Tabela 1. Área da Bacia Amazônica - Critérios hidrográficos para cada um dos seis países.

\begin{tabular}{|crc|}
\hline País & Área $\left(\mathrm{km}^{2}\right)$ & Percentual $(\%)$ \\
\hline Venezuela & $46.611,43$ & 0,78 \\
Equador & $105.111,88$ & 1,77 \\
Colômbia & $327.845,73$ & 5,53 \\
Bolívia & $732.378,66$ & 12,36 \\
Peru & $981.657,40$ & 16,57 \\
Brasil & $3.730 .677,30$ & 62,97 \\
Total & $\mathbf{5 . 9 2 4 . 2 8 2 , 4 2}$ & $\mathbf{1 0 0}$
\end{tabular}

Fonte: Adaptado de GEO... (2008).

Neste relatório (GEO..., 2008) são expostas as dificuldades ao representar os limites da Amazônia, utilizando vários critérios de definição para as suas fronteiras. Esses critérios são ecológicos ou biogeográficos (usa o bioma floresta tropical úmida e subtropical sul-americano), político-administrativo, ou seja, a área compreendida pelos limites político-administrativos de diferente hierarquia estabelecidos para cada país e definidos como parte da sua Amazônia e o critério hidrográfico, considerando a Bacia Amazônica, como a conjunção de várias sub e microbacias hidrográficas de inúmeras ordens que conformam o que se denomina de Bacia Hidrográfica Amazônica.

Deste modo, a drenagem da Bacia Amazônica, de acordo com Cunha (2006), está a cargo de três grandes centros de alimentação: Planalto das Guianas, Planalto Brasileiro e Cordilheira dos Andes, sendo deste último principalmente a água advinda da drenagem superficial e do derretimento das massas de gelo. Nessa diversidade fisiográfica regional, Mendes (1992) afirma que as maiores acumulações de gelo estão presentes em áreas de alta latitude e em áreas de elevadas altitudes. Essa paisagem está associada a uma diferença positiva entre as taxas de precipitação de gelo, que são maiores que a de evaporação. Por esse motivo é importante conhecer a dinâmica das geleiras amazônicas e todos os processos de formação, acumulação e perda (ablação) a que estão submetidas. De acordo com Ribeiro et al. (2017), nos trópicos existem geleiras na América do Sul (da Bolívia à Venezuela), África (Kilimanjaro, Monte Quênia e Rwenzori) e Oceania (Papua Ocidental). Somente os Andes possuem 99\% das massas de gelo localizadas na região tropical, cuja área de cobertura chega aproximadamente a $2.500 \mathrm{~km}^{2}$, sendo $70 \%$ no Peru, 20\% na Bolívia e 10\% no Equador, na Colômbia e Venezuela (Figura 2). 
Figura 2. Localização das geleiras da Amazônia.

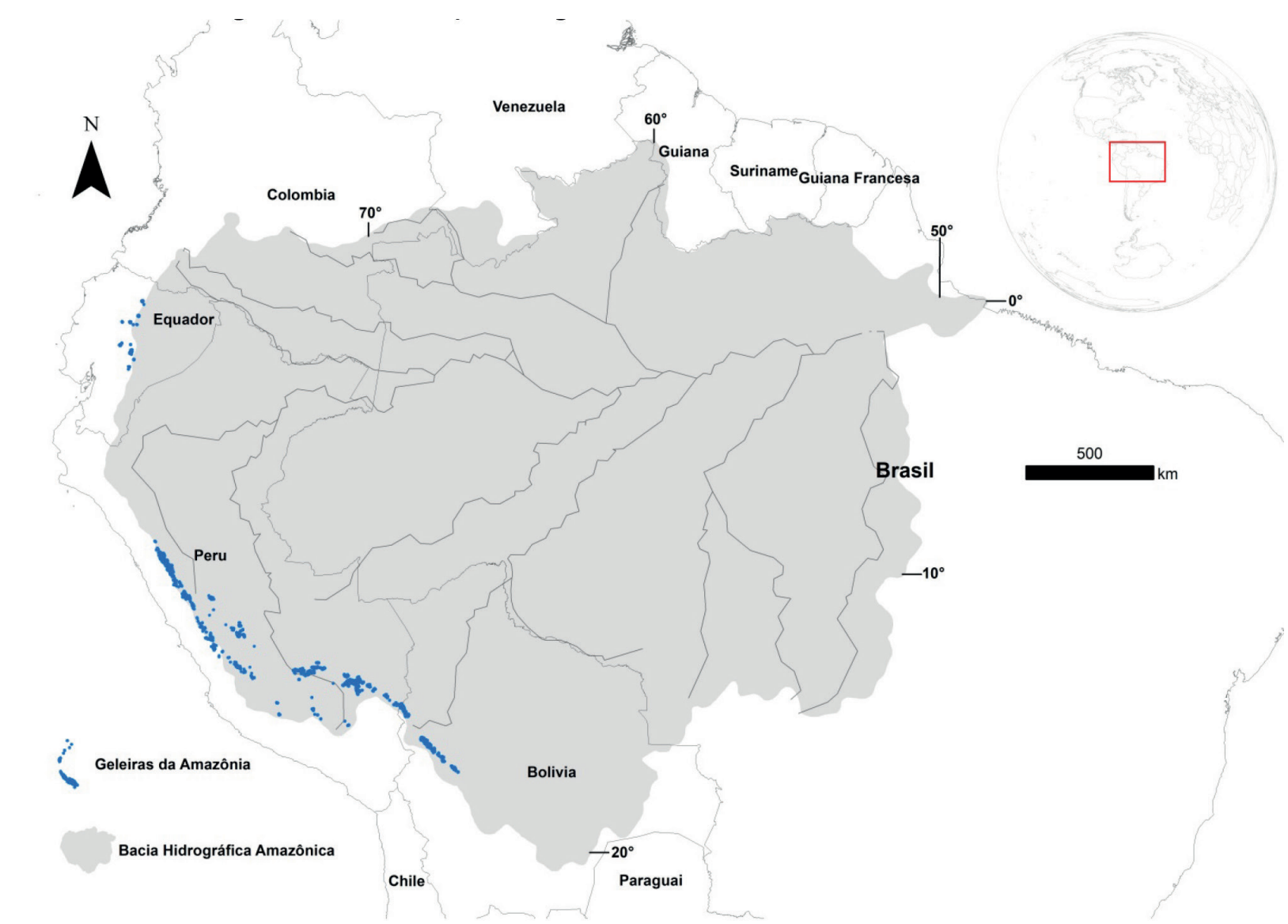

Fonte: Para representação das geleiras da Amazônia utilizaram-se dados do GLIMS (Global Land Ice Measurements from Space, em inglês) obtidos no banco de dados disponível na página GLIMS Glacier Database (http://glims.colorado.edu/glacierdata/).

Sendo assim, são dois os elementos característicos da distribuição dessas geleiras tropicais: precipitação e altitude. O primeiro está associado às condições de massas de ar úmidas em direção às montanhas, gerando um ambiente climático para formação das geleiras. O segundo, vinculado principalmente à linha de equilíbrio altitudinal (LEA), que determina a altitude limite para existência das geleiras na linha abaixo do pico das montanhas, são os fatores primordiais controladores dessa fisiografia (RIBEIRO et al., 2017).

Cálculos de mudanças globais no escoamento de geleiras em 56 bacias de drenagem glacializadas ao redor do globo até os anos de 2100, bem como o impacto que pode gerar o fluxo glacial nessas bacias, foram realizados por Huss e Hock (2018). Esses autores identificaram que, dentre as 56 bacias analisadas, a Bacia Amazônica apresenta menos de 1\% de sua área glacializada, justamente a cabeceira do Rio Amazonas, localizada nos Andes. Por essa característica, afirmam os autores, o derretimento é de impacto desprezível, de acordo com seus resultados, embora Mcclain e Naiman (2008) argumentem sobre a complexidade multifacetada das influências andinas na hidrologia, biogeoquímica e ecologia para o sistema hidrográfico do Rio Amazonas, pois somente nas últimas duas décadas que soergueram estudos dessa natureza tomando como base essas interconexões. Goicochea (1996) observou que, em 40 anos (1955 a 1996), houve um retrocesso considerável em algumas geleiras das cordilheiras do Peru, um recuo médio anual de 
$4 \mathrm{~m}$, situação esta apresentada pela geleira Quehuisha, Cordilheira Chila, na área da nascente do Rio Amazonas, na qual o desaparecimento da superfície de neve permanente é quase total.

Uma das argumentações que podem explicar o atual fenômeno de deglaciação para as geleiras da Amazônia está associada à alta de temperatura na baixa atmosfera sobre a região. Analisando dados de temperatura de 11 estações meteorológicas da região amazônica, Ribeiro et al. (2018) identificaram uma tendência de aquecimento sobre a região com aumento de aproximadamente $+0,24^{\circ} \mathrm{C}$ por década, de 1962 a 2009. Há também estudos que apontam aquecimento na troposfera média e alta nos trópicos em níveis mais elevados do que o previsto para a superfície da terra (BRADLEY et al., 2006). Esse cenário é corroborado por Thompson et al. (2011), apoiados em registros de núcleos de gelo tropicais de alta resolução e tempo, coletados em vários locais de diferentes níveis topográficos. Para esses autores, os registros indicam que as temperaturas na superfície e nas proximidades das geleiras aumentam mais em altitudes mais altas.

Outra argumentação está associada ao desmatamento na região amazônica. O debate sobre mudanças climáticas na Amazônia, em especial a brasileira, guarda um papel muito importante do desmatamento, pois este indica que as fontes dos rios na Cordilheira dos Andes podem sofrer diminuição significativa no suprimento de água (precipitação) como resultado da redução da umidade atmosférica (BUNYARD, 2005; RIBEIRO et al., 2017). Fatores como as queimadas (ARTAXO et al., 2006), o crescente avanço da fronteira da monocultura de grãos (CASTRO, 2005), da pecuária das grandes fazendas (GRAIN; INSTITUTE FOR AGRICULTURE AND TRADE POLICY, 2018) $)^{4}$, do latifúndio e da grilagem de terras, das grandes plantas de geração hidrelétricas (FEARNSIDE, 2015) e dos grandes empreendimentos da mineração (WANDERLEY, 2012) ao crescente processo de urbanização difusa (TRINDADE JUNIOR, 2015), são elementos sine qua non à devastação de leste a oeste, de norte a sul da rosa dos ventos sobre a região.

Apesar do dissentimento do atual governo brasileiro sobre o cenário de desmatamento da Floresta Amazônica, o Inpe divulgou estimativa de desmatamento para os nove estados da Amazônia Legal Brasileira para o ano de 20195. Como pode ser observado na Figura 3, o valor estimado é de $9.762 \mathrm{~km}^{2}$ para o período de agosto de 2018 a julho de 2019 (barra destacada em vermelho na figura). Esse valor, de acordo com o referido instituto, representa um aumento de $29,54 \%$ em relação à taxa de desmatamento apurada pelo Prodes 2018 , que foi de $7.536 \mathrm{~km}^{2}$. Didaticamente, o Inpe (2019) explica que existem duas formas distintas do processo de desmatamento: uma feita por corte raso e a outra por degradação florestal. A primeira forma é o processo que resulta na remoção completa da cobertura florestal em curto intervalo de tempo; a segunda trata-se da degradação progressiva, que é mais lenta e mais difícil de detectar usando imagens de satélites, pois envolve vários passos que podem levar alguns anos (INPE, 2019).

\footnotetext{
${ }^{4}$ Estudo da Organização não governamental Grain e do Institute for Agriculture and Trade Policy (IATP) aponta que em menos de duas décadas as maiores empresas globais no ramo de carne e de derivados de leite de origem animal (frigoríficos e laticínios) superarão em fonte de emissões de gases de efeito estufa (GEE), empresas do ramo dos combustíveis fósseis, como a ExxonMobil, Shell e BP ltd. Neste caso, sensivelmente, a participação do Brasil é significativa, só a JBS emite 280.2 milhões de toneladas, para um cenário onde a Política Nacional sobre Mudança do Clima estimou um redução de emissões brasileiras de GEE entre 36,1\% e 38,9\% das emissões projetadas até 2020, compromisso voluntário do Brasil junto à ConvençãoQuadro das Nações Unidas sobre Mudança do Clima (BRASIL, 2009).

5 Você pode conferir lendo a nota técnica neste link: http://www.obt.inpe.br/OBT/

noticias/a-estimativa-da-taxa-de-desmatamento-por-corte-raso-para-a-amazonia-legal-em-2019-e-de-9-762-km2
} 
Perceba, no gráfico de linhas com marcadores (Figura 3), que historicamente os estados de Mato Grosso e do Pará são aqueles com maior contribuição ao desmatamento da Floresta Amazônica; em especial no estado do Pará, na Amazônia Oriental (observe o mapa de calor na Figura 3, que mostra espacialização do desmatamento em 2019), é onde se encontram níveis elevados de alteração na cobertura vegetal e no uso e ocupação da terra de diversas ordens. Adami et al. (2015) mostram que o desflorestamento mapeado entre os anos de 2008 e 2011 no estado do Pará, cerca de 55\%, tornou-se pastagem, aproximadamente 9 mil quilômetros quadrados, e, de acordo com IBGE (2013), no ano de 2010 o tipo de uso da terra como pastagens totalizou uma extensão de $187.308 \mathrm{~km}^{2}$, ou seja, 15,2\% do território estadual, com destaque para a mesorregião do sudeste paraense com área de $119.186,58 \mathrm{~km}^{2}$ ocupada por pastagem.

Figura 3. Taxas de desmatamento na Amazônia Legal Brasileira.

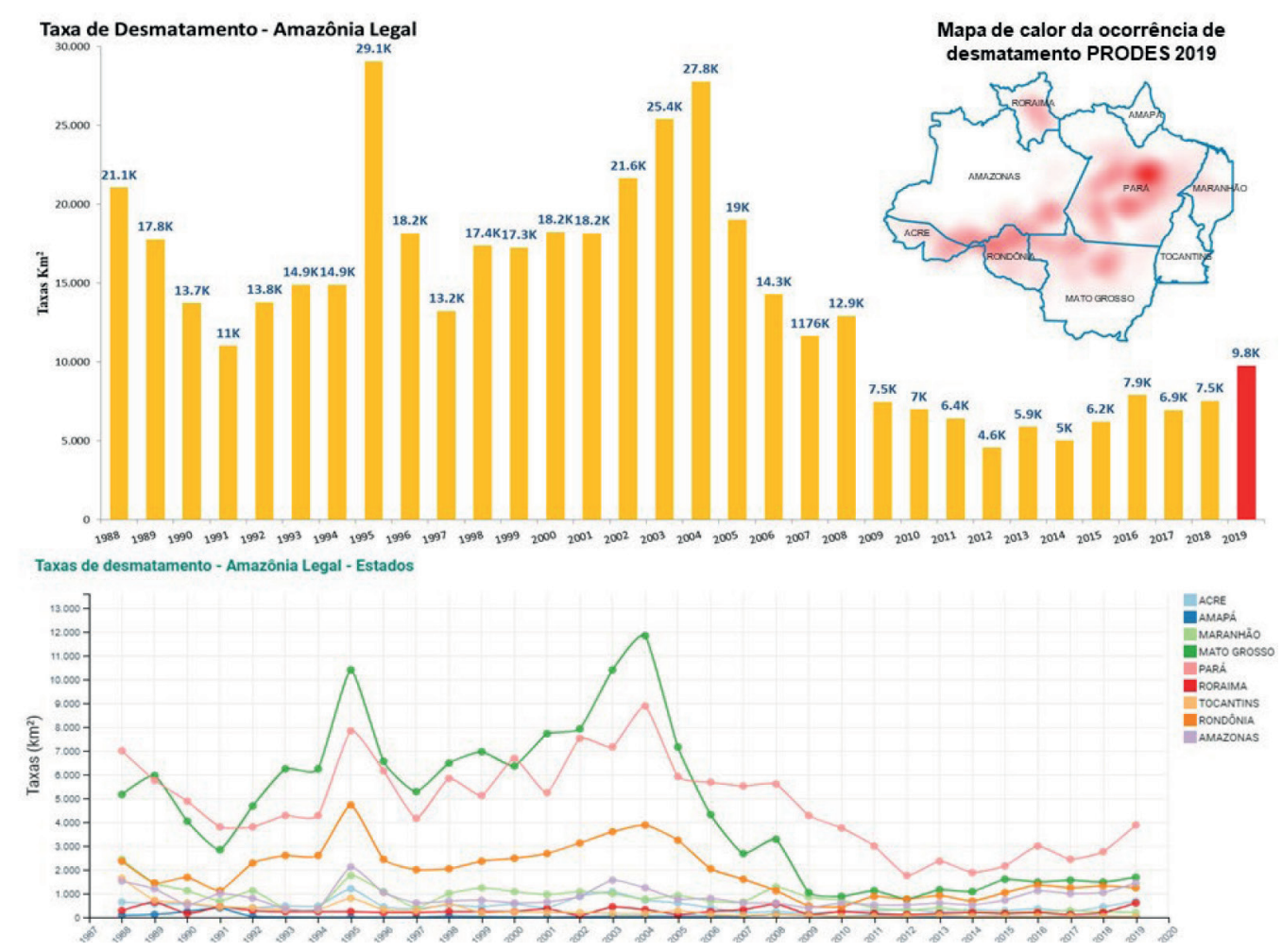

Fonte: Barras verticais - Série histórica das taxas de desmatamento na Amazônia Legal Brasileira desde 1988 (PRODES Analógico) até 2019 (PRODES Digital); linhas com marcadores - Exibe as taxas de desmatamento por estado; mapa de calor - Espacialização do desmatamento na Amazônia Legal Brasileira em 2019. Esses e demais dados estão disponíveis na plataforma (terrabrasilis.dpi.inpe.br) (ASSIS et al., 2019).

A estimativa do desmatamento da Floresta Amazônica calculada pelo Inpe para 2019 é a maior desde o ano de 2008, o que representa um retorno a índices de desmatamento extremamente elevados, algo que se podia acreditar já superado, que não voltaria a acontecer, pois essa suposta superação gerava um ambiente de compleição nas esferas de decisão. Não obstante, Viola (2010) elenca alguns fatores que caminham nessa perspectiva, como, por exemplo, a substancial capacidade de monitoramento, fiscalização e repressão do desmatamento, bem como criação de leis que salvaguardam a floresta em pé, criação de extensas áreas protegidas (Resex, Parna, estações ecológicas, etc.) tanto no âmbito da união quanto dos estados da Amazônia, atuação de grandes 
organizações não governamentais (ONGs) internacionais e nacionais, ou seja, havia certo consenso no imaginário de uma parte do setor de massa crítica nacional para quem o desmatamento da Floresta Amazônica havia chegado, finalmente, há um processo de estabilização.

\section{...e influencia parâmetros geológicos e hidrogeológicos, biogeoquímico e ecológico da Bacia Amazônica}

Pesquisas sobre a região amazônica, levando em consideração as interconexões e interdependência, trânsito dos sedimentos muito importante para fertilização do solo da planície, que vêm desde os Andes, atravessando várias regiões de formações geológicas sedimentares diferentes, ainda são poucas para abarcar tamanha complexidade. Ab'Saber (2005) explica que esse trânsito de sedimentos pode chegar a 3 milhões de toneladas por dia na altura da Baía de Marajó, no Golfão Marajoara. Mcclain e Naiman (2008) afirmam, por sua vez, que esse material biogeoquímico é o principal suporte para vida ecológica realizada pelos rios tributários, fruto da história orogênica dos Andes que solapou o sentido do curso do Amazonas.

Sacek (2014) reconstruiu os processos que orientaram a mudança no sentido do fluxo da rede de drenagem da Bacia Amazônica por meio de modelo numérico tridimensional associando processos superficiais, isostasia e espessamento crustal. $\mathrm{O}$ autor propõe que a reversão da drenagem para leste, durante o Mioceno, foi principalmente fruto de processos de superfície e do soerguimento do alto estrutural andino ao invés da dinâmica topográfica da convecção do manto. Por outro lado, Rossetti (2014) mostra que a história neotectônica da planície amazônica possivelmente está relacionada à movimentação intraplaca, e os dados sedimentares e paleontológicos presentes na literatura atualmente apontam um cenário muito mais complexo para o teatro evolucionário amazônico, caracterizado por modificações sucessivas no ambiente físico e na biota associada, em consequência de mudanças no nível relativo do mar, no clima e no comportamento tectônico (ROSSETTI; TOLEDO, 2007).

Ab'Saber (2005) mostra que o conjunto que fica entre a região cisandina (região interna dos Andes) e o Golfão Marajoara, interconectada por mesma drenagem, não se trata apenas da forte homogeneidade da expressão florestal, mas também da rede de drenagem como um leque muito amplo entre a região cisandina e o começo do estrangulamento por terrenos cristalinos do Planalto das Guianas e do Planalto Brasileiro Setentrional. Antes da barreira andina e com a presença de sedimentos de várias idades (Paleozoico, Siluriano, Devoniano, Carbonífero e sedimentos marinhos do Mioceno) acredita-se que a região amazônica era um grande canal por onde transcorria o mar de oeste a leste. De acordo com Figueiredo et al. (2007), a bacia sedimentar da Foz do Amazonas corresponde à mais extrema bacia ao norte da margem continental brasileira, abrange o litoral do estado do Amapá e parte do litoral noroeste do estado do Pará. Assim, desde o Neomioceno (10,7 Ma) até o presente desenvolveu-se uma portentosa edificação sedimentar terrígena trazida desde a região cisandina pelo Rio Amazonas, conhecida como "Cone do Amazonas".

Por análise de dados sedimentológicos e palinológicos de dois testemunhos de sedimentos coletados no leste da Colômbia e noroeste do Brasil, evidencia-se que águas marinhas provenientes do mar do Caribe cobriram parte da região amazônica pelo menos duas vezes durante o Mioceno (25 a 5 milhões de anos) (JARAMILLO et al., 2017). Com o início do dobramento dos Andes foi possível proporcionar imensa sedimentação terrígena flúvio-lacustre originando 
grandes territórios para a Formação Alter do Chão e Barreiras. No mapa representado na Figura 4 é mostrada a dimensão do Sistema Aquífero Amazonas, já com a inclusão do aquífero Alter do Chão (UNESCO, 2007) formando o maior sistema de água doce transfronteiriço do mundo. O sistema aquífero transfronteiriço Amazonas está localizado sobre as províncias hidrogeológicas sul-americanas denominadas de Amazonas e Orinoco, situada entre os países Brasil, Colômbia, Bolívia, Peru, Equador e Venezuela, com extensão de aproximadamente $3.950 .000 \mathrm{~km}^{2}$, dos quais $2.000 .000 \mathrm{~km}^{2}$ são contribuição da Formação Alter de Chão e 1.200 .000 km², da Formação Içá (UNESCO, 2007).

Figura 4. Sistema Aquífero Amazonas (elaboração dos autores).

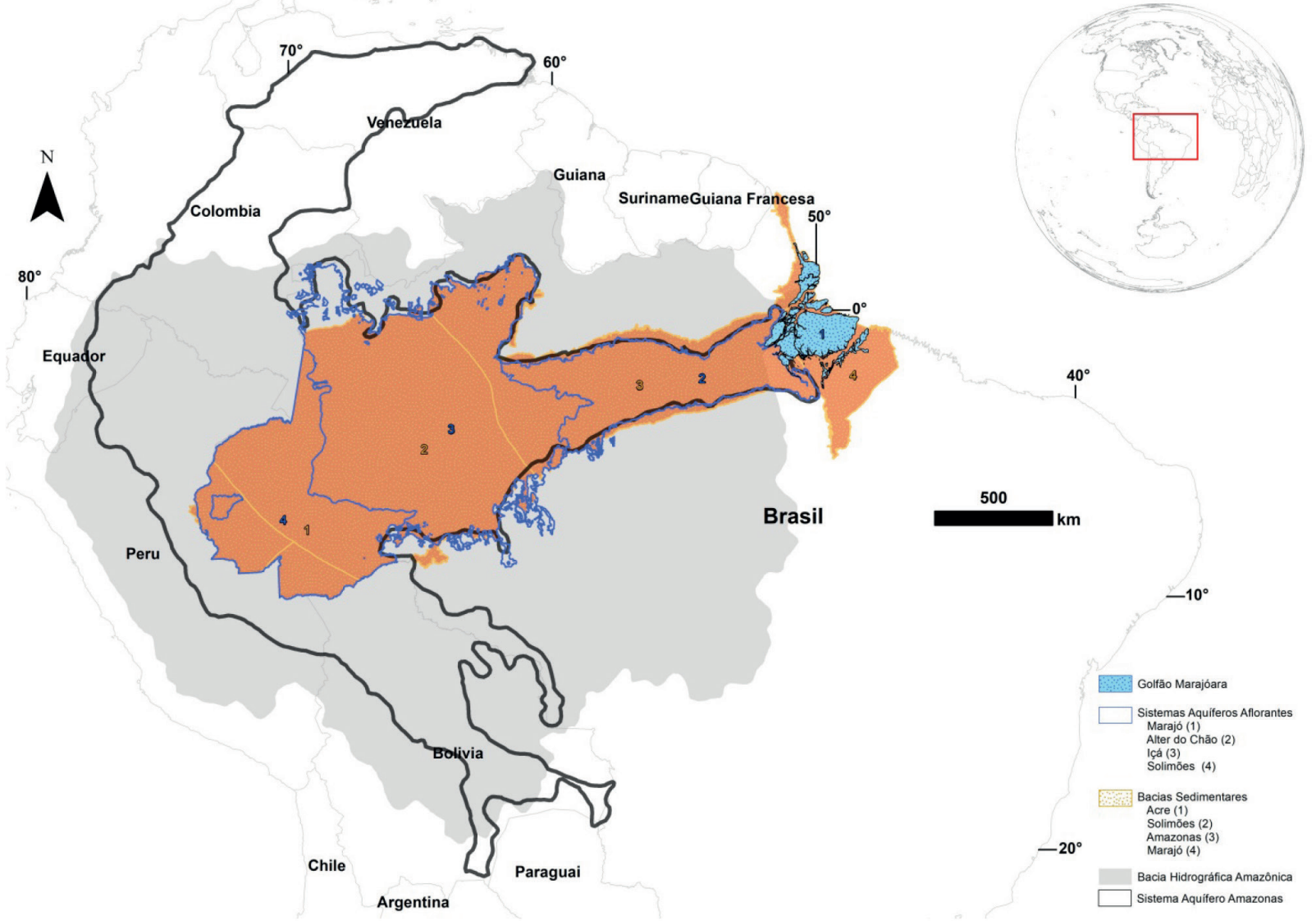

Fonte: Para representação do Sistema Aquífero Amazonas utilizou-se a publicação da Série ISARM Américas No 1 (International Shared Aquifer Resource Management), UNESCO (2007). Para representação dos sistemas aquíferos aflorantes utilizaram-se dados da Gerência de Águas Subterrâneas (GESUB) da Agência Nacional de Águas (http://www.metadados.inde.gov.br). Para representação das bacias sedimentares utilizaram-se os dados do Sistema de Geociências (GeoSGB) do Serviço Geológico do Brasil - CPRM (http://geosgb.cprm.gov.br/downloads).

De acordo com Diniz et al. (2014), as classes taxonômicas em termos de aquíferos podem ser definidas pelo agrupamento de unidades geológicas que armazenam e transmitem águas subterrâneas de forma semelhante, ou seja, criando as unidades hidrolitológicas, ou domínios hidrogeológicos. No caso do Sistema Aquífero Amazonas, sua delimitação possivelmente seguiu essa compreensão taxonômica. Como apontam Diniz et al. (2014), a unidade hidrolitológica é uma unidade de referência, tridimensional, com limites e dimensões arbitrárias. Não possui limites concretos, muitas características se superpõem às de outras hidrolitológias e existem em número infinitamente grande. 
A magnitude do aquífero Alter do Chão é ressaltada por Abreu et al. (2013), que denominaram de Sistema Aquífero Grande Amazônia (Saga). Eles afirmam o imenso potencial de água subterrânea para a região e para o Brasil e os aspectos estratégicos e geopolíticos que envolvem o tema. Essa província hidrogeológica (contornos azuis na Figura 4), formada pelas bacias sedimentares do Acre, Solimões, Amazonas e Marajó, compõe-se de uma área de 1.305 .000 km². Destacam ainda, Abreu et al. (2014), a dificuldade da aplicação do conceito de bacia hidrográfica como disposto na Política Nacional de Recursos Hídricos (Lei no 9.433 de 1997) pelo deslocamento difuso e complexidade do fluxo.

Assim, no contexto amazônico, o sensível equilíbrio entre a floresta e os recursos hídricos é responsável pelo regime de chuvas na região. De acordo com os autores supracitados, o Saga é responsável por $80 \%$ do mecanismo do ciclo hidrológico na Amazônia, e, associado a isso, o balanço hídrico da Amazônia está no saldo positivo de 8.076 trilhões de litros de água por ano que chega às regiões Centro-Sul e Sul do País pelo escoamento atmosférico (deslocamento da umidade). Não obstante os altos índices pluviométricos que ocorrem na Amazônia, na ordem de $2.500 \mathrm{~mm}$ por ano (embora Fisch et al., 1998, apontem que na fronteira entre Brasil, Colômbia e Venezuela o total anual pode atingir $3.500 \mathrm{~mm}$ ), as águas subterrâneas são intensamente utilizadas, estimando-se que cerca de 70\% dos núcleos urbanos são abastecidos por essa fonte hídrica (FREITAS et al., 2014), porém, para os Andes, Mark et al. $(2010,2017)$ apontam que há sérios riscos hídrico-sociais nos centros urbanos andinos, em especial em cidades do Peru, pela falta de abastecimento de água proveniente do degelo.

\section{Geopolítica Pan-Amazônica: do consenso das commodities ao derretimento das geleiras}

Refletindo sobre a dimensão internacional da Amazônia, Aragón (2018) mostra a complexidade dessa região até mesmo para denominá-la. Pan-Amazônia, Amazônia Continental, Amazônia Sul-Americana, Grande Amazônia e outros termos correlatos fazem referência à Amazônia como um todo, isso porque cada país diferencia sua Amazônia nacional.

Assim, partindo da singularidade de um pensamento latino-americano sobre o território, a região amazônica é a materialização de múltiplos territórios. Como reflete Haesbaert (2020), a Amazônia é a corporificação do território como categoria da prática, seja do ponto de vista dos agentes hegemônicos - estados nacionais e empresas multi e transnacionais -, seja do ponto de vista dos povos originários e das populações das cidades na floresta e da floresta, da planície ao cisandino, onde tecem inúmeras relações de poder, força motriz de diversas formas de desenvolvimento. Aliás desenvolvimento, nas palavras de Porto-Gonçalves (2009), é sinônimo quase sempre de (des)envolvimento, ou seja, aminguamento, apoucamento, prostração, mas também carrega conotação de degelo, desmatamento e mudança do clima.

No âmbito da geopolítica regional, a Organização do Tratado de Cooperação Amazônica (OTCA), criada após a assinatura do Tratado em Brasília no final da década de 1970, formada pelos oito países que compartilham a Amazônia: Bolívia, Brasil, Colômbia, Equador, Guiana, Peru, Suriname e Venezuela, constituiu, em 2003, um secretariado permanente (MARMOLEJO, 2008). O bloco socioambiental tem em seu escopo, principalmente, a pauta do desenvolvimento 
sustentável entre os signatários para a região. No entanto, Aragón (2018) questiona a efetividade dessa pauta, pois as políticas de todos os países de atuação da Pan-Amazônia são elaboradas e disseminadas sem coordenação, tratando-se apenas de iniciativas nacionais, muito pelo desconhecimento de cada país sobre a porção amazônica do país vizinho.

De fato, como apontam Silva e Dantas (2012), a OTCA, enquanto organização de um secretariado permanente, foi uma resposta à ideia de internacionalização da Amazônia. Zevallos (1993) explica que em 1989, na Conferência do Meio Ambiente de Haya, o presidente francês François Mitterrand propôs:

A criação de uma alta autoridade mundial para questões ambientais com capacidade de ingerência, o que poderia vir a limitar as soberanias nacionais sobre bens considerados de interesse para a humanidade, como a Amazônia. Diante de tal situação, o Brasil solicitou (e logicamente conseguiu) o apoio dos países signatários do TCA. Isso ocorreu em Manaus, a 6 de maio de 1989, na chamada Declaração da Amazônia, emitida por todos os chefes de Estado dos países signatários; o anfitrião foi o Presidente José Sarney. Nessa ocasião foi rechaçada a internacionalização e aprovada a cooperação externa, desde que não questionasse a soberania dos países membros do Tratado (ZEVALLOS, 1993, p.129).

Esse argumento tinha no escopo a tentativa de tornar o espaço amazônico, a exemplo da Antártica ou o fundo dos mares, espaço ambiental de interesse internacional, reduzindo, portanto, o domínio político-territorial dos países dessa região. Nesse sentido, sobre a ótica da geopolítica amazônica, atualmente pressionados pelos debates sobre mudanças climáticas globais, os estados que compõem a Pan-Amazônia se veem obrigados a encarar novamente questões como essa, não apenas a partir de suas dificuldades internas socioespaciais ou econômico-territoriais, mas agora coordenados. De acordo com o estudo levantado pelo PNUMA/OTCA (GEO..., 2008), estima-se que a população dessa imensa área está na ordem de 38 milhões de pessoas, a qual Aragón (2018) calcula ser mais de três vezes a população de Portugal, quase a população da Argentina, mais que a do Canadá, e mais de duas vezes a do Chile, em uma área de aproximadamente 7.413.827 $\mathrm{km}^{2}$, como pode ser visto na Tabela 2 , segundo critério político-administrativo para definição da superfície da Amazônia, que representa 54\% do território dos oito países-membros da OTCA (GEO..., 2008).

A OTCA é uma tentativa de integração dos estados nacionais que compartilham as fronteiras amazônicas contra gerenciamento externo à região. Ações para integração da América Meridional datam desde o final do século XIX. A geopolítica regional no século XIX, como mostra o Barão de Marajó (ABREU, 1992), já lançava ideias de abertura e interligação da região amazônica conectando o Pacífico e o Atlântico, passando pela Cordilheira dos Andes, em um percurso que teria seu início na Bolívia, pegando o curso do Rio Amazonas até saída pelo Golfão Marajoara para alcançar a Europa. É nesse âmbito que surge a concepção da Estrada de Ferro Madeira-Mamoré. Para além do objetivo principal de encerrar a celeuma entre Brasil e Bolívia ${ }^{6}$,

\footnotetext{
6 De acordo com Barão de Marajó (ABREU, 1992), o Tratado de Amizade, Limites, Navegação, Comércio e Extradição (Tratado de Ayacucho) entre Bolívia e Brasil, assinado em 27 março 1867, teve o objetivo principal de apaziguar os conflitos fronteiriços entre esses países, a questão do Acre, gerada principalmente pela extração do látex que alimentava a economia extrativista da borracha. A Estrada de Ferro Madeira-Mamoré foi colocada no pacote do tratado de paz, em que a construção da ferrovia ficou a cargo do Brasil.
} 
a ferrovia a ser construída tinha outros objetivos explícitos, como o de criar uma via de circulação de pessoas e mercadorias principalmente produtos bolivianos para o leste da Amazônia, entende-se naquele momento as cidades de Manaus e Belém como entrepostos para alcançar o mercado europeu. Não olvide que na Amazônia existiram outras estradas de ferro, como a Ferrovia do Tocantins (funcionamento de 1890 até 1967) e a Ferrovia Belém-Bragança (funcionamento de 1883 até 1965), esta tida como um exemplo de estrada de ferro na Amazônia à época, diminuindo distâncias e custos de circulação de mercadoria e pessoas (CRUZ, 1955).

Tabela 2. Superfície da Amazônia segundo critério político-administrativo.

\begin{tabular}{|ccc|}
\hline País & Área do país $\left(\mathrm{km}^{2}\right)$ & Superfície da área amazônica $(\%)$ \\
\hline Bolívia & 1.098 .581 & 724.000 \\
\hline Brasil & 8.514 .876 & 5.034 .740 \\
\hline Colômbia & 1.141 .748 & 477.274 \\
\hline Equador & 283.561 & 115.613 \\
\hline Guiana & 214.960 & 214.960 \\
\hline Peru & 1.285 .216 & 651.440 \\
\hline Suriname & 142.800 & 142.800 \\
\hline Venezuela & 916.445 & 53.000 \\
\hline Total & $\mathbf{1 3 . 5 9 8 . 1 8 7}$ & $\mathbf{7 . 4 1 3 . 8 2 7}$ \\
\hline
\end{tabular}

Fonte: GEO... (2008).

No entanto, apesar de ter no discurso a sustentabilidade e o desenvolvimento econômico em paridade com o social, a organização do tratado impulsiona ou mesmo constrói políticas regionais de desenvolvimento que em nada muda o paradigma da degradação ambiental para sustentar um modelo econômico, que é a antítese do seu discurso. Exemplo disso é o projeto Iniciativa para Integração da Infraestrutura Regional Sul-Americana (IIRSA). Esse projeto foi organizado em dez eixos de integração e desenvolvimento, para interligar o Oceano Atlântico ao Oceano Pacífico, construindo uma série de infraestrutura como estradas, hidrovias e ferrovias, redes de comunicação, portos, aeroportos e construção de barragens hidrelétricas e integração energética.

Porto-Gonçalves e Quental (2012) mostram que a origem da IIRSA, como uma estratégia de integração física da América do Sul, data dos anos 1990 como proposta para inserir a região competitivamente na economia mundial, quando foram formulados no Brasil os eixos nacionais de integração e desenvolvimento (Enid). A lógica era incorporar novas áreas à dinâmica comercial global, mantendo-se como força hegemônica sul-americana. Argumentam ainda esses autores que os Planos Plurianuais (PPAs) do governo federal foram estabelecidos a partir da noção de Enids, em programas como: Brasil em Ação (1996-1999), Avança Brasil (2000-2003) e Brasil de Todos (2004-2007), que tiveram como destaque obras de infraestrutura, como a recuperação e construção de novas rodovias, a construção de hidrovias, instalação de gasodutos, entre outros.

Castro (2012) mostra como todas essas políticas de múltiplas escalas sempre caminharam no fortalecimento dos estados nacionais para entrarem no jogo econômico de geração de divisas em detrimento da soberania das nações sobre os seus recursos naturais, consorciado, por tabela, em processos desterritorializantes sobre os povos da região, assim, em sua reflexão: 
A Pan-Amazônia torna-se um espaço de repercussão das dinâmicas nacionais, da intervenção de megaprojetos que acabam por desestruturar uma dada ordem social e ambiental existente e disponibilizar, assim, novas fronteiras de terras e recursos naturais. [...] O Estado tem optado pela solução mais tradicional de desenvolvimento - o que se tem revelado ineficaz social e ambientalmente -, que é a construção de grandes obras de infraestrutura, usando argumentos que supervalorizam os benefícios do desenvolvimento (CASTRO, 2012, p. 59).

Ainda na reflexão dessa autora, Castro (2012) afirma ter sido a Amazônia transformada em uma fronteira de commodities. Porto-Gonçalves e Quental (2012) argumentam que o objetivo da IIRSA está acanastrado a um novo cenário geopolítico e econômico onde a Ásia e a China, em particular, passam a desempenhar importante centralidade, pois a interconexão física do continente insere-se como estratégia de resposta às novas e crescentes demandas asiáticas por commodities. Exemplo cabal, em âmbito regional amazônico, é a construção da Rodovia Transoceânica, que atravessa a Floresta Amazônica e a Cordilheira dos Andes até alcançar o litoral peruano, para constituir um corredor de commodities dos produtos brasileiros para o mercado asiático. Ou seja, uma inversão da direção e sentido, se no século XIX o intuito era rasgar a Amazônia para escoamento de mercadorias para Europa pelo atlântico, hoje rasga-se para ter acesso pelo Pacífico ao comércio asiático.

Um setor de commodities importante nessa geopolítica é a mineração, com atividades desde a foz do grande rio até os Andes. No estado Pará, no município de Barcarena, o Instituto Evandro Chagas (IEC) identificou danos ambientais e riscos à saúde humana ocasionados por escoamento de efluentes (lama vermelha) a partir do transbordamento de bacias de deposição de resíduos sólidos do processo de beneficiamento de bauxita (INSTITUTO EVANDRO CHAGAS, 2018). Na região do Baixo Amazonas, Wanderley (2012) evidencia sérios problemas socioambientais nos municípios de Oriximiná e Juruti pela extração de bauxita, provocando a contaminação dos cursos de água (rios e lagos), o desflorestamento de mata virgem na área do projeto, o deslocamento compulsório de famílias, a proibição de acesso às áreas de uso coletivo, a construção de uma infraestrutura que exclui as populações locais, o surgimento de regras e normas territoriais que inviabilizaram as práticas tradicionais de uso do espaço.

Há também sérios problemas ambientais causados pela mineração na região amazônica do Peru. Wanderley (2012) cita como exemplo os impactos sobre a terra e alteração do uso e ocupação do solo, contaminação da água, conflitos em áreas mineradas, desterritorialização que levaram à emergência de mobilizações coletivas na forma de movimentos sociais identificados como antimineração. Situação ainda mais claudicante mostram Brenning e Azocar (2010) em relação à mineração sobre as geleiras de rocha nos Andes do Chile. Esses autores estudaram, com base em fotografias aéreas e imagens de satélites, a redução desse tipo de geleira vinculada à atividade. Apontam os autores a construção de bacia de rejeitos responsável pela diminuição e até mesmo pelo desaparecimento de 15 geleiras de rocha situadas próximas das minas do maior grupo mineralógico daquele país. Apesar do gelo das montanhas chilenas não integrarem a conjuntura da Bacia Amazônica, pode-se evidenciar o panorama, ou melhor, o cenário conflituoso, entretanto, que cria condições geradoras de mudanças do clima. 
Vuille et al. (2018) identificam grandes projetos de irrigação para a agricultura de exportação ao longo dos desertos costeiros peruanos, aumentando a demanda sobre as águas que drenam de uma das principais cordilheiras dos Andes no Peru, a Cordilheira Blanca. Por conseguinte, a agricultura de subsistência baseada em culturas como alfafa e batata é cada vez mais substituída por culturas de exportação (aspargos, arroz, abacate), cultivadas nesses grandes projetos. De acordo com Cornejo (2011), o Peru é um dos 20 países com maior vulnerabilidade às mudanças do clima, pela própria dimensão ambiental geradora de conflitos socioambientais impulsionados pela avidez econômica de vários setores sobre os ecossistemas encontrados nas montanhas das geleiras amazônicas. É nesse sentido que Hoffmann (2012) aponta que a vulnerabilidade às mudanças climáticas das zonas de altas montanhas sul-americanas está associada principalmente à condição de pobreza das populações ali existente.

Thompson et al. (2011) ressaltam a necessidade científica e social de entender os fatores e respostas do regime climático tropical passado e presente para obter melhor compreensão dos fatores climáticos que controlam a perda recente e acelerada de campos de gelo permanentes nos trópicos. Ao ponto de Hanshaw e Bookhagen (2014) afirmarem que pouco ainda é conhecido acerca das escalas de tempo e as condições de equilíbrio da maioria das geleiras dos Andes e como isso pode afetar o balanço de massa, e as consequências que podem gerar para o ciclo hidrográfico da Bacia Amazônica. Por fim, Aragón (2018) enfatiza que o desmatamento da floresta andina poderá gerar sérias consequências para o resto da região, ainda mais em se tratando da contaminação por mercúrio e petróleo, carreados rio abaixo, nos rios da Amazônia nos países andinos.

Mcclain e Naiman (2008) argumentam que as ligações entre montanhas e terras baixas estão ameaçadas pela expansão das atividades humanas na Amazônia andina, com consequências que eventualmente são sentidas a milhares de quilômetros de distância. Sendo assim, a história recente da Amazônia é a materialização da emblemática expansão capitalista neoliberal para novas fronteiras de acumulação. É um fiel reflexo da concepção de região subalterna, encanastrada ao papel destinado à América-Latina, desde o extrativismo do período mercantilista - estágio inicial do capitalismo -, até o neoextrativismo, corroborando com o que Svampa (2013) chama de consenso de commodities. Esses modelos, do passado e do presente, deixam seus traços não somente na economia - o aspecto subserviente da região em relação a outras regiões do globo -, mas também significativos traços na cultura e na diversidade dos povos, bem como na heterogeneidade da paisagem amazônica.

\section{Conclusão}

A conjuntura ambiental das geleiras tropicais sul-americanas, as geleiras da Amazônia, apresenta inúmeras modificações complexas que podem originar consequências negativas significativas para a região amazônica, especialmente na rede hidrográfica, além das populações amazônicas. Os efeitos da mudança do clima e os impactos ambientais são compensáveis pela ótica da financeirização dos recursos naturais via lógica de commodities em mercados financeiros.

A rede hidrográfica, desde a região cisandina até o Golfão Marajoara, é interconectada por uma ampla drenagem superficial ou lençol de águas subterrâneas (o imenso Sistema Aquífero 
Amazonas). Em matéria de transporte de sedimentos são provenientes dos Andes inúmeros materiais e substâncias que se depositam nas margens dos rios, fertilizando as águas e propiciando um rico recurso para a biodiversidade aquática.

A manutenção das geleiras da Amazônia deve ter a mesma compreensão e seriedade que se tem sobre a importância de manter a Floresta Amazônica em pé. A subjugação dos efeitos do derretimento das geleiras amazônicas sobre os aspectos geobioquímico e ecológico pode levar, entretanto, a efeitos mais significativos do ponto de vista socioterritorial e político, pois as cidades, sociedades e povos diretamente afetados com essas mudanças não podem esperar. E, em se tratando de Amazônia, ainda são importadas as lógicas e discursos de resultados, se deram certos ali, há grandes possibilidades de darem certo aqui, preâmbulo da tragédia.

Portanto, a geopolítica da mudança do clima nessa grande região Pan-Amazônia não pode deixar de lado os rasgos de impactos ambientais nas geleiras da Amazônia, algo negligenciado no passado, porém hoje, mediante o atual cenário climático conflituoso, é imprescindível realizar reflexões e estudos sobre as possíveis consequências para a região.

\section{Referências}

ABREU, F. A. M.; CAVALCANTE, I. N.; DUARTE, A. A. M.; MATTA, M. A. S. O Sistema Aquífero Grande Amazônia - SAGA: definição, compartimentação e estimativas preliminares de reservas. In: REUNIÃO ANUAL DA SBPC, 66., 2014, Rio Branco, AC. Anais / resumos... São Paulo: SBPC, 2014. Disponível em: http://www.sbpcnet.org.br/livro/66ra/PDFs/arq_3432_1484.pdf. Acesso em: 29 jun. 2019.

ABREU, F. A. M.; CAVAlCANTE, I. N.; MATTA, M. A. S. O Sistema Aquífero Grande Amazônia SAGA: um imenso potencial de água subterrânea no Brasil. In: CONGRESSO INTERNACIONAL DE MEIO AMBIENTE SUBTERRÂNEO, 3., 2013, São Paulo. Anais... Disponível em: https://aguassubterraneas.abas.org/asubterraneas/article/download/27831/18054. Acesso em: 29 jun. 2019.

ABREU, J. C. G. As Regiões Amazônicas, estudos chorographicos dos estados do Gram Pará e Amazonas. 2. ed. Belém, PA: Secretaria de Estado da Cultura. 1992. 404 p. (Série Lendo o Pará, n. 12).

AB'SÁBER, A. N. Problemas da Amazônia brasileira. Estudos Avançados, v. 19, n. 53, p. 7-35, abr. 2005.

ADAMI, M.; GOMES, A. R.; COUTINHO, A. C.; ESQUERDO, J. C. D. M.; VENTURIERI, A. Dinâmica do uso e cobertura da terra no estado do Pará entre os anos de 2008 a 2012. In: SIMPÓSIO BRASILEIRO DE SENSORIAMENTO REMOTO, 17., 2015, João Pessoa. Anais... São José dos Campos: INPE, 2015. p. 7028-7035.

ARAGÓN, L. E. A Dimensão internacional da Amazônia: um aporte para sua interpretação. Revista Nera, ano 21, n. 42, p. 14-33, 2018.

ARTAXO, P.; OLIVEIRA, P. H.; LARA, L. L.; PAULIQUEVIS, T. M.; RIZZO, L. V.; PIRES JUNIOR, C.; PAIXÃO, M. A.; LONGO, K. M.; FREITAS, S.; CORREIA, A. L. Efeitos climáticos de partículas de aerossóis biogênicos e emitidos em queimadas na Amazônia. Revista Brasileira de Meteorologia, v. 21, n. 3, p. 1-22, 2006. 
ASSIS, L. F. F. G.; FERREIRA, K. R.; VINHAS, L.; MAURANO, L.; ALMEIDA, C.; CARVALHO, A.; RODRIGUES, J.; MACIEL, A.; CAMARGO, C. TerraBrasilis: a spatial data analytics infrastructure for large-scale thematic mapping. ISPRS International Journal of Geo-Information, v. 8, n. 11, p. 513, 2019.

BRADLEY, R. S.; VUILLE, M.; DIAZ, H. F.; VERGARA, W. Threats to water supply in the tropical Andes. Science, v. 312, n. 5781, p. 1755-1756, 2006.

BRASIL. Presidência da República. Lei no 12.187, de 29 de dezembro de 2009. Institui a Política Nacional sobre Mudança do Clima (PNMC) e dá outras providências. Brasília, 29 dez. 2009.

BRASIL. Secretaria de Assuntos Estratégicos, Presidência da República. Água e desenvolvimento sustentável recursos hídricos fronteiriços e transfronteiriços do Brasil. Brasília, maio de 2013. (Série Estudos Estratégicos).

BRENNING, A.; AZOCAR, G. F. Minería y glaciares rocosos: impactos ambientales, antecedentes políticos y legales, y perspectivas futuras. Revista de Geografia Norte Grande, n. 47, p. 143-158, dez. 2010.

BUNYARD, P. Climate and the Amazon: consequences for our planet. In: INTERNATIONAL CONFERENCE ON THE IMPACT OF CLIMATE CHANGE ON HIGH-MOUNTAIN SYSTEMS, 1. 2005, Bogota. Proceedings... Bogotá: IDEAM, 2005. p. 109-121.

CASTRO, E. Dinâmica socioeconômica e desmatamento na Amazônia. Novos Cadernos NAEA, v. 2, n. 1, p. 5-39, 2005.

CASTRO, E. Expansão da fronteira, megaprojetos de infraestrutura e integração sul-americana. Caderno CRH, v. 25, n. 64, p. 45-62, 2012.

CORNEJO, A. C. ¿Por qué ha aumentado la conflictividad social en el Perú? El caso del sector minero. Revista de Ciencias Sociales Universidad de Costa Rica, v. 133-134, p. 125-140, 2011. Disponível em: https://revistas.ucr.ac.cr/index.php/sociales/article/view/3864/3737. Acesso em: 21 jun. 2018.

CRUZ, E. A estrada de ferro de Bragança: visão social, política e econômica. Belém, PA: SPVEA, 1955. $161 \mathrm{p}$.

CUNHA, S. B. Bacias hidrográficas. In: CUNHA, S. B.; GUERRA, A. J. T. (Org.). Geomorfologia do Brasil. 4. ed. Rio de Janeiro: Bertrand Brasil, 2006. 392 p.

DINIZ, J. A. O.; PAULA, T. L. F.; MONTEIRO, A. B.; FEITOSA, F. A. C.; CARDOSO, A. C. Taxonomia hidrogeológica - unidades básicas de referência. Revista Águas Subterrâneas, 2014. Suplemento. Anais do XVII Congresso Brasileiro de Águas Subterrâneas. Disponível em: https://aguassubterraneas.abas.org/ asubterraneas/article/view/28287. Acesso em: 22 jan. 2020.

FEARNSIDE, P. M. Hidrelétricas na Amazônia: impactos ambientais e sociais na tomada de decisões sobre grandes obras. Manaus: INPA, 2015. v. 2. 296 p.

FIGUEIREDO, J. J. P.; ZALÁN, P. V.; SOARES, E. F. Bacia da Foz do Amazonas. Boletim de Geociências da Petrobras, v. 15, n. 2, p. 299-309, maio/nov. 2007.

FISCH, G.; MARENGO, J. A.; NOBRE, C. A. Uma revisão geral sobre o clima da Amazônia. Acta Amazônica, v. 28, n. 2, p. 101, jun. 1998.

FREITAS, M. A.; DINIZ, J. A. O.; PEIXINHO, F. C. Mapa hidrogeológico da Amazônia Legal - escala 1:2.500.000. Revista Águas Subterrâneas, 2014. Suplemento. Anais do XVII Congresso Brasileiro de Águas Subterrâneas, Belo Horizonte, MG. Disponível em: https://aguassubterraneas.abas.org/asubterraneas/article/download/27745/17992. Acesso em: 22 jan. 2020. 
GEO Amazônia: perspectivas do meio ambiente na Amazônia. Panamá: PNUMA; Brasília, DF: OTCA, 2008. $323 \mathrm{p}$.

GLIMS: Global Land Ice Measurements from Space. 2019. Disponível em: https://www.glims.org/. Acesso em: 20 jun. 2019.

GOICOCHEA, Z. N. El origen del río Amazonas. Espacio y Desarrollo, n. 8, p. 115-160, 1996. Disponível em: http://revistas.pucp.edu.pe/index.php/espacioydesarrollo/article/view/8002. Acesso em: 15 jan. 2020.

GRAIN; INSTITUTE FOR AGRICULTURE AND TRADE POLICY - IATP. Emissões impossíveis: como a indústria de carne e de laticínios está aquecendo o planeta. 2018. Disponível em: https://grain. org/e/6011. Acesso em: 23 jan. 2020.

HAESBAERT, R. Território(s) numa perspectiva latino-americana. Journal of Latin American Geography, v. 19, n. 1, p. 141-151, jan. 2020,

HANSHAW, M. N.; BOOKHAGEN, B. Glacial areas, lake areas, and snow lines from 1975 to 2012: status of the Cordillera Vilcanota, including the Quelccaya Ice Cap, Northern Central Andes, Peru. The Cryosphere, v. 8, p. 359-376, 2014.

HOFFMANN, D. Cambio climático y desarrollo sostenible en regiones de Montaña de Bolivia. Revista Virtual REDESMA, v. 6, n. 1, Dez. 2012.

HUSS, M.; HOCK, R. Global - scale hydrological response to future glacier mass loss. Nature Climate Change, v. 8, p. 135-140, 2018.

INSTITUTO BRASILEIRO DE GEOGRAFIA E ESTATÍSTICA - IBGE. Uso da terra no Estado do Pará - Relatório técnico. Projeto Levantamento e Classificação do Uso da Terra. Rio de Janeiro, 2013. $149 \mathrm{p}$.

INSTITUTO EVANDRO CHAGAS - IEC. Nota técnica SAMAM-IEC 002/2018. Ananindeua, PA, 2018. 10 p. Disponível em: https://www.iec.gov.br/coletiva-hydro/nota-tecnica-samam-iec-002-2018-compressed/. Acesso em: 29 jan. 2020.

INSTITUTO NACIONAL DE PESQUISAS ESPACIAIS - INPE. Estudo do INPE indica que o rio Amazonas é $140 \mathrm{~km}$ mais extenso do que o Nilo. Notícia, 01 jul. 2008. Disponível em: http://www.inpe. br/noticias/noticia.php?Cod_Noticia=1501. Acesso em: 13 set. 2019.

INSTITUTO NACIONAL DE PESQUISAS ESPACIAIS - INPE. Metodologia utilizada nos projetos PRODES e DETER. 2019. 33 p. Disponível em: http://www.obt.inpe.br/OBT/assuntos/programas/amazonia/prodes/pdfs/Metodologia_Prodes_Deter_revisada.pdf. Acesso em: 26 jan. 2020.

INTERGOVERNMENTAL PANEL ON CLIMATE CHANGE - IPCC. Climate Change 2014 Synthesis Report Summary for Policymakers. Fifth Assessment Report (AR5). 2014. Disponível em: https://www. ipcc.ch/site/assets/uploads/2018/02/AR5_SYR_FINAL_SPM.pdf. Acesso em: 01 jun. 2019.

JARAMILlO, C.; ROMERO, I.; D’APOLITO, C.; BAYONA, G.; DUARTE, E.; LOUWYE, S.; ESCOBAR, J.; LUQUE, J.; CARRILLO-BRICEÑO, J. D.; ZAPATA, V.; MORA, A.; SCHOUTEN, S.; ZAVADA, M.; HARRINGTON, G.; ORTIZ, J.; WESSELINGH, F. P. Miocene flooding events of western Amazonia. Science Advances, v. 3, e1601693, p. 1-11, 2017.

MARK, B. G.; BURY, J.; MCKENZIE, J. M.; FRENCH, A.; BARAER, M. Climate change and tropical Andean Glacier recession: evaluating hydrologic changes and livelihood vulnerability in the Cordillera Blanca, Peru. Annals of the Association of American Geographers, v. 100, n. 4, p. 794-805, 2010. 
MARK, B. G.; FRENCH, A.; BARAER, M.; BURY, J.; YOUNG, K. R.; POLK, M. H.; WIGMORE, O.; LAGOS, P.; CRUMLEY, R.; MCKENZIE, J. M.; LAUTZ, L. Glacier loss and hydro-social risk in the Peruvian Andes. Global and Planetary Change, n. 159, p. 61-76, 2017.

MARMOLEJO, F. J. R. Relatório de gestão. Brasília, DF: Organização do Tratado de Cooperação Amazônica, 2008. 20 p.

MCCLAIN, M.; NAIMAN, R. J. Andean influences on the biogeochemistry and ecology of the Amazon River. BioScience, v. 58, p. 325-338, 2008.

MENDES, J. C. Elementos de estratigrafia. São Paulo: T. A. Queiros, 1992. 566 p. (Coleção Biblioteca de Ciências Naturais, v. 12).

PORTO-GONÇALVES, C. W. Entre América e Abya Yala - tensões de territorialidades. Desenvolvimento e Meio Ambiente, n. 20, p. 25-30, jul./dez. 2009.

PORTO-GONÇALVES, C. W.; QUENTAL, P. A. Colonialidade do poder e os desafios da integração regional na América Latina. Polis - Revista de la Universidad Bolivariana, v. 11, n. 31, jan.-abr. 2012.

RIBEIRO, R. R.; SIMÕES, J. C.; RAMIREZ, E. The Amazon glaciers. In: GODONE, D. Glacier evolution in a changing World. S.1.: IntechOpen, 2017. DOI: 10.5772/intechopen.70490.

RIBEIRO, R. R.; SIMÕES J. C.; RAMIREZ, E.; TAUPIN, J.; ASSAYAG, E.; DANI, N. Accumulation rate in a tropical Andean glacier as a proxy for northern Amazon precipitation. Theoretical and Applied Climatology, v. 132, p. 569-578, 2018.

ROSSETTI, D. F. The role of tectonics in the late Quaternary evolution of Brazil. Earth Science Reviews, v. 139, p. 362-389, Dec. 2014.

ROSSETTI, D. F.; TOLEDO, P. M. Environmental changes in Amazonia as evidenced by geological and paleontological data. Revista Brasileira de Ornitologia, v. 15, n. 2, p. 251-264, 2007.

SACEK, V. Drainage reversal of the Amazon River due to the coupling of surface and lithospheric processes. Earth and Planetary Science Letters, v. 401, p. 301-312, 2014.

SILVA, S. T.; DANTAS, F. A. C. Águas na Amazônia e Direito Ambiental Internacional. Novos Estudos Jurídicos, v. 17, n. 1, p. 39-47, abr. 2012.

SOARES, L. C. Hidrografia. In: GEOGRAFIA do Brasil. Rio de Janeiro: IBGE, 1991. v. 1.

SVAMPA, M. Consenso de los Commodities y lenguajes de valoración en América Latina. Revista Nueva Sociedad, v. 244, mar.-abr. 2013.

THOMPSON, L. G.; MOSLEY-THOMPSON, E.; DAVIS, M. E.; BRECHER, H. H. Tropical glaciers, recorders and indicators of climate change, are disappearing globally. Annals of Glaciology, v. 52, n. 59, 2011.

TRINDADE JUNIOR, S-C C. Cidades e centralidades urbanas na Amazônia: dos diferentes ordenamentos territoriais ao processo de urbanização difusa. Revista Cidades, v. 12, n. 21, 2015.

UNESCO. Sistemas Acuíferos Transfronterizos en la Américas - evaluación preliminar. Montevideo: Washington, DC, 2007. 178 p. (Serie ISARM Américas, n. 1).

VIOLA, E. A política climática global e o Brasil: 2005-2010. Revista Tempo do Mundo, v. 2, n. 2, 2010. 
VUILLE, M.; CAREY, M.; HUGGEL, C.; BUYTAERT, W.; RABATEL, A.; JACOBSEN, D.; SORUCO, A.; VILLACIS, M.; YARLEQUE, C.; TIMM, O. E.; CONDOM, T.; SALZMANN, N.; SICART, J.-E. Rapid decline of snow and ice in the tropical Andes - impacts, uncertainties and challenges ahead. EarthScience Reviews, v. 176, p. 195-213, 2018.

WANDERLEY, L. J. Movimentos sociais em área de mineração na Amazônia Brasileira. E-cadernos CES [Online], n. 17, 2012. Disponível em: http://journals.openedition.org/eces/1117. Acesso em: 25 jan. 2020.

ZEVAllos, E. A. Da Amazônia ao Pacífico cruzando os Andes. Estudos Avançados, v. 7, n. 17, p. 117169, abr. 1993. 
